\title{
Changes in Holstein cow milk and serum proteins during intramammary infection with three different strains of Staphylococcus aureus
}

Yunee Kim', Heba Atalla², Bonnie Mallard ${ }^{2}$, Claude Robert ${ }^{3}$ and Niel Karrow ${ }^{1 *}$

\begin{abstract}
Background: Staphylococcus aureus is one of the most prevalent pathogens to cause mastitis in dairy cattle. Intramammary infection of dairy cows with $S$. aureus is often subclinical, due to the pathogen's ability to evade the innate defense mechanisms, but this can lead to chronic infection. A sub-population of S. aureus, known as small colony variant (SCV), displays atypical phenotypic characteristics, causes persistent infections, and is more resistant to antibiotics than parent strains. Therefore, it was hypothesized that the host immune response will be different for SCV than its parental or typical strains of S. aureus. In this study, the local and systemic immune protein responses to intramammary infection with three strains of $S$. aureus, including a naturally occurring bovine SCV strain (SCV Heba3231), were characterized. Serum and casein-depleted milk cytokine levels (interleukin-8, interferon$\gamma$, and transforming growth factor- $\beta 1$ ), as well as serum haptoglobin concentrations were monitored over time after intramammary infection with each of the three $S$. aureus strains. Furthermore, comparative proteomics was used to evaluate milk proteome profiles during acute and chronic phases of $S$. aureus intramammary infection.

Results: Serum IL-8, IFN- $\gamma$, and TGF- $\beta 1$ responses differed in dairy cows challenged with different strains of $S$. aureus. Changes in overall serum haptoglobin concentrations were observed for each S. aureus challenge group, but there were no significant differences observed between groups. In casein-depleted milk, strain-specific differences in the host IFN- $\gamma$ response were observed, but inducible IL-8 and TGF- $\beta 1$ concentrations were not different between groups. Proteomic analysis of the milk following intramammary infection revealed unique host protein expression profiles that were dependent on the infecting strain as well as phase of infection. Notably, the protein, component-3 of the proteose peptone (CPP3), was differentially expressed between the $S$. aureus treatment groups, implicating it as a potential antimicrobial peptide involved in host defense against $S$. aureus intramammary infection.
\end{abstract}

Conclusions: Intramammary infection of dairy cattle with S. aureus causes an up-regulation of serum and milk immune-related proteins, and these responses vary depending on the infecting strain.

\section{Background}

Mastitis, an inflammatory condition of the mammary gland, typically arises as a result of intramammary infections. In lactating dairy cattle, mastitis results in considerable monetary losses to the dairy industry due to depressed milk yield and quality, reduced reproductive performance, treatment, and pre-mature culling [1,2]. Staphylococcus aureus is a Gram-positive, opportunistic,

\footnotetext{
* Correspondence: nkarrow@uoguelph.ca

${ }^{1}$ Center for Genetic Improvement of Livestock, Department of Animal and Poultry Science, University of Guelph, Guelph, Ontario, N1G 2W1, Canada Full list of author information is available at the end of the article
}

and contagious bacterium that is one of the most prevalent causes of mastitis in both humans and cattle [3]. Although infection can result in obvious clinical mastitis, $S$. aureus often evades the immune response resulting in a sub-clinical chronic infection that can persist for the life of the animal [4]. Classically, S. aureus is characterized as an extracellular pathogen [5]. However, an increasing number of studies elude to its ability to invade and survive within various host cell types, including mammary epithelial cells, neutrophils, and macrophages [6-8]; this may contribute to its persistence in various $S$. aureus-induced diseases [7]. Small colony
C Biomed Central

() 2011 Kim et al; licensee BioMed Central Ltd. This is an Open Access article distributed under the terms of the Creative Commons Attribution License (http://creativecommons.org/licenses/by/2.0), which permits unrestricted use, distribution, and reproduction in any medium, provided the original work is properly cited. 
variants (SCVs) of $S$. aureus may be particularly endowed for persistent survival by residing in host cells as they are characterized by slow-growth and atypical colony morphology, and are often over-looked by standard laboratory assays [9]. It has been previously demonstrated that SCVs can survive within professional and non-professional phagocytic cells $[8,10]$, are more persistent than typical S. aureus strains [11], and are difficult to treat with conventional antibiotics [9].

Given that different $S$. aureus strains appear to utilize unique infection and survival strategies, we hypothesized that the host immune response will also vary in accordance with the infecting strain. To elucidate potential differences in host responses to $S$. aureus infection, the present study was carried out to investigate the kinetic response of key cytokines in serum and casein-depleted milk, as well as serum haptoglobin over a 21-day period following intramammary infection with three strains of S. aureus. Additionally, a comparative proteomics platform was used to resolve the proteome of caseindepleted milk during acute and chronic phases of infection, and to identify differentially expressed proteins with potential immunomodulating effects. The $S$. aureus strains used for intramammary infection were: the SCV Heba3231, a naturally occurring SCV isolated from a dairy cow with history of chronic mastitis with atypical phenotypic properties [10], the 3231 parent strain displaying typical morphological and biochemical properties [10], and Newbould 305 (ATCC 29740), a teat skin strain that causes clinical bovine mastitis [12,13] that is frequently used as a model for studying $S$. aureusinduced mastitis.

\section{Results}

Serum IL-8, IFN- $\boldsymbol{\gamma}$, TGF- $\beta 1$, and haptoglobin response to $S$. aureus intramammary infection

Lactating dairy cattle were challenged with one of three $S$. aureus strains and the local and systemic host immune responses were characterized by monitoring cytokine kinetics and using a proteomics approach to identify proteins that may play a role in host defense (Figure 1). Significant IL-8 expression in the serum was not evident for any of the challenge groups until day 14 post-infection (pi) (Figure 2A). Animals challenged with Newbould 305 and Heba 3231 exhibited significantly higher IL- 8 expression on days 14 and 21 pi relative to levels on day $0(\mathrm{P}<0.01)$. Interestingly, animals challenged with Parent 3231 showed a significant decrease in IL-8 expression on day $14(\mathrm{P}<0.01)$, and no significant change on day $21 \mathrm{pi}$, relative to day 0 . Significant differences in IL-8 expression between the three challenge groups were observed on days 14 and $21 \mathrm{pi}$, with both Newbould 305 and Heba 3231 challenge groups having significantly higher IL-8 expression than the

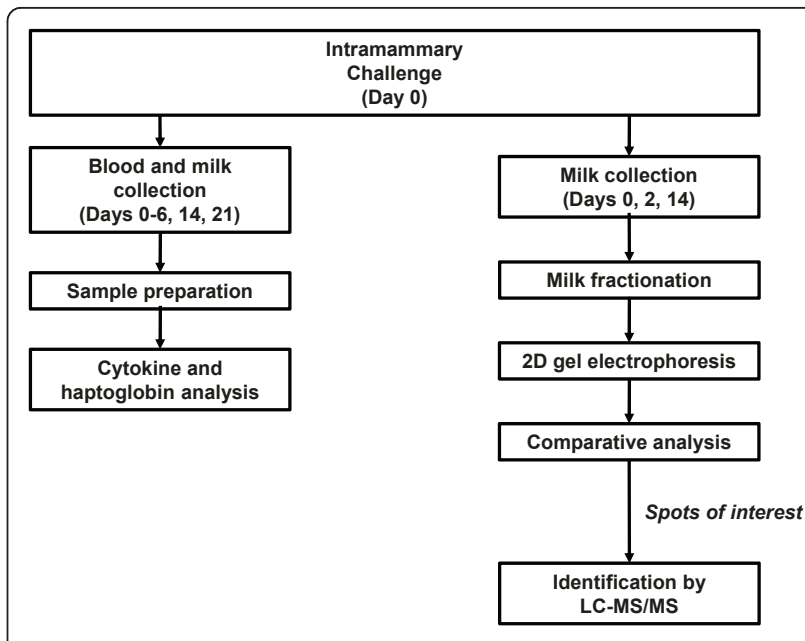

Figure 1 Flow chart of study outline.

Parent 3231 group $(\mathrm{P}<0.01)$. Milk IL-8 levels were not statistically significantly different from baseline (day 0 ) levels at any time during the study (data not shown).

Serum concentrations of IFN- $\gamma$ were significantly upregulated in the Newbould 305 challenge group during days 1-6 pi relative to serum IFN- $\gamma$ levels at day $0(\mathrm{P}<$ 0.01 ) (Figure 2B). On day 21 pi however, all challenge groups showed significant increases in IFN- $\gamma$ expression compared to day 0 (Newbould 305 and Parent 3231, $\mathrm{P}<$ 0.05; Heba 3231, $\mathrm{P}<0.01)$. Significant differences between challenge groups occurred on days 1-6 pi, whereby animals challenged with Newbould 305 had significantly higher serum IFN- $\gamma$ levels compared to animals challenged with Heba $3231(\mathrm{P}<0.01)$.

Serum TGF- $\beta 1$ expression was significantly downregulated in animals challenged with Parent 3231 throughout days 1-6 and 14 pi relative to day $0(\mathrm{P}<$ 0.01 ) (Figure $2 \mathrm{C}$ ). In contrast, on day $14 \mathrm{pi}$, the Newbould 305 and Heba 3231 challenge groups had significantly up-regulated expression $(\mathrm{P}<0.01$ and $\mathrm{P}<0.05$, respectively). On day $21 \mathrm{pi}$, the Heba 3231 challenge group was the only group to have significantly elevated expression of TGF- $\beta 1$ compared to levels at day $0(\mathrm{P}<$ $0.01)$. Significant differences in TGF- $\beta 1$ expression between the three challenge groups were observed on day 14 pi, with Newbould 305 and Heba 3231 groups having significantly higher TGF- $\beta 1$ levels compared to the Parent 3231 group $(\mathrm{P}<0.01)$, and on day $21 \mathrm{pi}$, with the Heba 3231 group having significantly higher TGF- $\beta 1$ expression compared to either Newbould 305 or Parent 3231 groups $(\mathrm{P}<0.01)$. Milk TGF- $\beta 1$ levels were not statistically significantly different from baseline at any time during the study period (data not shown).

Analysis of serum revealed significant elevations in haptoglobin concentrations within the first 24 hours pi for all three challenge groups $(\mathrm{P}<0.01)$ (Figure $2 \mathrm{E})$; 


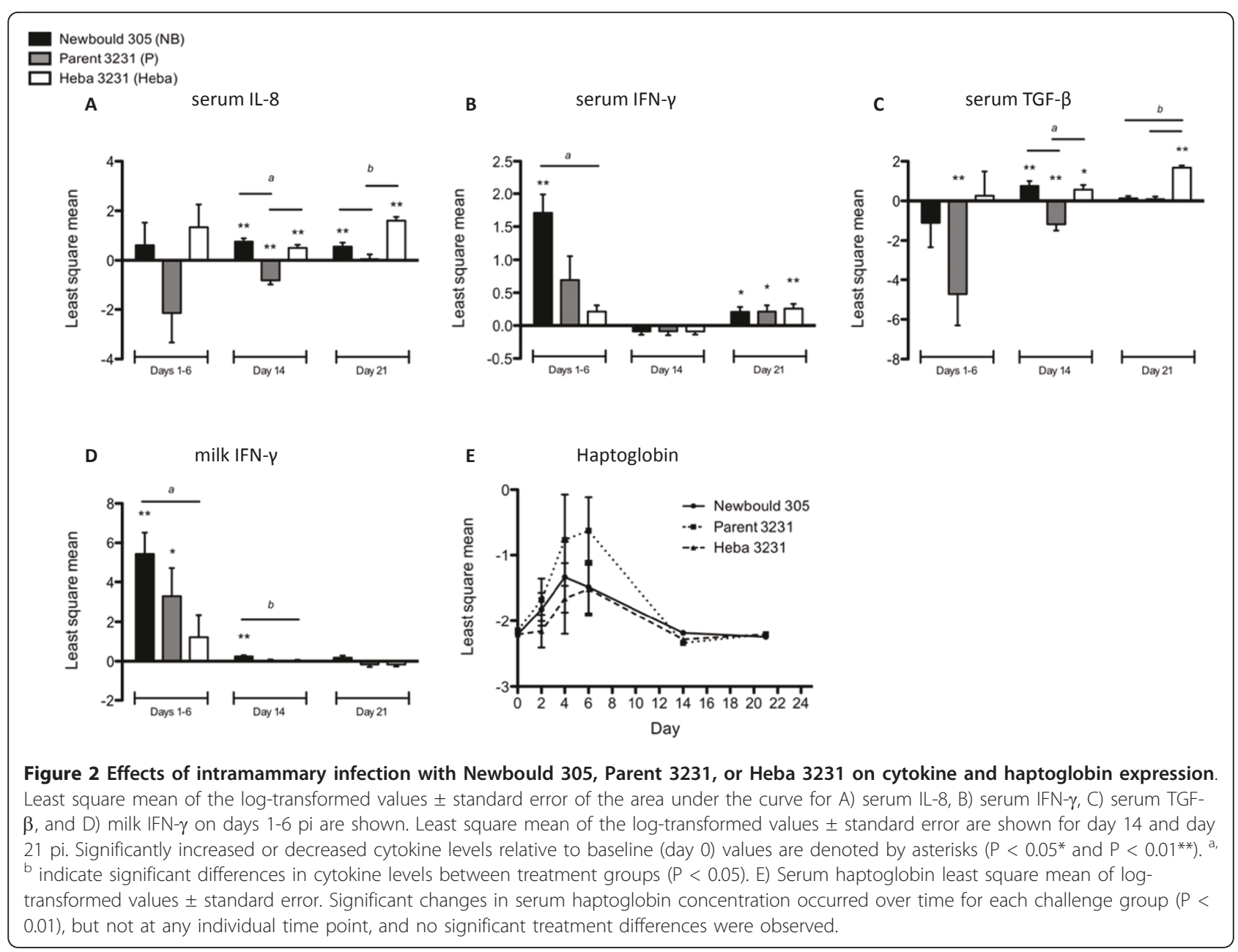

however, linear and orthogonal polynomial contrasts did not reveal any significant differences in haptoglobin responses between any of the challenge groups.

\section{Milk IL-8, IFN- $\gamma$ and TGF- $\beta 1$ response to $S$. aureus intramammary infection}

Significant changes in IL- 8 and TGF- $\beta 1$ expression were not observed in casein-depleted milk for any of the challenge groups at any time, when compared to levels on day 0 (data not shown). In contrast, IFN- $\gamma$ concentrations were significantly increased in animals challenged with $S$. aureus, but the response varied with the infection strain (Figure 2D). For example, IFN- $\gamma$ concentrations were increased in response to Newbould 305 on days 1-6 and day 14 pi relative to levels on day $0(\mathrm{P}<0.01)$, but not day 21 pi. The Parent 3231 challenge group also showed a significant increase in IFN- $\gamma$ expression on days 1-6 pi $(\mathrm{P}<0.05)$. No significant change in IFN- $\gamma$ expression was seen for the Heba 3231 challenge group at any sampling time. Significant differences between groups occurred on days 1-6 and day 14 pi, where the Newbould 305 challenge group had higher IFN- $\gamma$ expression compared to the Heba 3231 group $(\mathrm{P}<0.05)$.

\section{Milk proteome profiling following intramammary infection with $S$. aureus}

Milk proteome analyses by 2 -dimensional gel electrophoresis (2DE) revealed 29 protein spots that were differentially expressed on days 2 or $14 \mathrm{pi}$, relative to expression on day $0(\mathrm{P}<0.05)$ (Table 1$)$, with up-regulated expression occurring most frequently. In the Newbould 305 challenge group, there were 12 and 1 protein spots that were significantly induced on days 2 and 14 pi, respectively. In the group challenged with the Parent 3231 strain, 12 and 8 protein spots were significantly induced on days 2 and 14 pi, respectively. Lastly, for the Heba 3231 challenge group, no proteins were induced on day 2 pi, however, 8 protein spots were significantly induced on day 14.

Of the 29 spots that were differentially expressed during the acute or chronic phases of infection, only 1 spot was significantly differentially expressed over time and 
Table 1 Change in milk protein expression on 2 and 14 days post-intramammary infection with different S.aureus strains

\begin{tabular}{|c|c|c|c|c|}
\hline Spot I.D. & Trmt*Day & $\mathrm{LSM} \pm \mathrm{SEM}$ & p-vlaue & Direction \\
\hline \multirow[t]{2}{*}{11} & $P * 14$ & $0.03 \pm 0.01$ & 0.0205 & $\uparrow$ \\
\hline & Heba*14 & $0.02 \pm 0.01$ & 0.0382 & $\uparrow$ \\
\hline 12 & $P * 2$ & $0.05 \pm 0.02$ & 0.0127 & $\uparrow$ \\
\hline \multirow[t]{2}{*}{13} & $P^{*} 2$ & $0.02 \pm 0.01$ & 0.0206 & $\uparrow$ \\
\hline & Heba*14 & $0.02 \pm 0.01$ & 0.024 & $\uparrow$ \\
\hline 21 & $P * 14$ & $0.03 \pm 0.01$ & 0.0397 & $\uparrow$ \\
\hline 33 & $P * 2$ & $0.05 \pm 0.02$ & 0.0056 & $\uparrow$ \\
\hline \multirow[t]{2}{*}{35} & $N B^{*} 2$ & $0.02 \pm 0.004$ & 0.0041 & $\uparrow$ \\
\hline & Heba*14 & $0.01 \pm 0.005$ & 0.0467 & $\uparrow$ \\
\hline \multirow[t]{3}{*}{39 (CPP3) } & $P * 2$ & $0.02 \pm 0.007$ & 0.0476 & $\uparrow$ \\
\hline & $P * 14$ & $0.01 \pm 0.004$ & 0.0032 & $\uparrow$ \\
\hline & Heba*14 & $0.01 \pm 0.004$ & 0.0154 & $\uparrow$ \\
\hline 45 & $\mathrm{NB}^{*} 2$ & $0.01 \pm 0.004$ & 0.0122 & $\uparrow$ \\
\hline 131 & $\mathrm{NB}^{*} 2$ & $0.01 \pm 0.005$ & 0.031 & $\uparrow$ \\
\hline 141 & $N B^{*} 2$ & $0.04 \pm 0.01$ & 0.0296 & $\uparrow$ \\
\hline \multirow[t]{2}{*}{212} & $P * 2$ & $0.01 \pm 0.004$ & 0.0038 & $\uparrow$ \\
\hline & Heba*14 & $0.01 \pm 0.005$ & 0.0408 & $\uparrow$ \\
\hline \multirow[t]{2}{*}{220} & $P * 2$ & $0.04 \pm 0.01$ & 0.0214 & $\uparrow$ \\
\hline & Heba*14 & $0.01 \pm 0.005$ & 0.0304 & $\uparrow$ \\
\hline 222 & $N B^{*} 2$ & $0.02 \pm 0.009$ & 0.0384 & $\uparrow$ \\
\hline 227 & $P * 2$ & $0.008 \pm 0.003$ & 0.0127 & $\uparrow$ \\
\hline \multirow[t]{3}{*}{235 (СРP3) } & $P * 2$ & $0.03 \pm 0.01$ & 0.0241 & $\uparrow$ \\
\hline & $P^{*} 14$ & $0.01 \pm 0.006$ & 0.0492 & $\uparrow$ \\
\hline & Heba*14 & $0.02 \pm 0.006$ & 0.0127 & $\uparrow$ \\
\hline 244 & $P * 14$ & $-0.008 \pm 0.002$ & 0.0016 & $\downarrow$ \\
\hline \multirow[t]{2}{*}{250} & $N B^{*} 2$ & $0.007 \pm 0.003$ & 0.0417 & $\uparrow$ \\
\hline & $N B^{*} 14$ & $0.01 \pm 0.005$ & 0.0535 & $\uparrow$ \\
\hline 251 & $P * 2$ & $0.04 \pm 0.02$ & 0.0449 & $\uparrow$ \\
\hline ( $\beta$-casein precursor) & $P * 14$ & $0.008 \pm 0.002$ & 0.0025 & $\uparrow$ \\
\hline 341 & $P * 14$ & $0.02 \pm 0.004$ & 0.0006 & $\uparrow$ \\
\hline 343 & $P * 14$ & $0.02 \pm 0.009$ & 0.0188 & $\uparrow$ \\
\hline 346 & $N B^{*} 2$ & $0.02 \pm 0.01$ & 0.0331 & $\uparrow$ \\
\hline 349 (СРP3) & $N B^{*} 2$ & $0.01 \pm 0.004$ & 0.0084 & $\uparrow$ \\
\hline 350 & $N B^{*} 2$ & $0.02 \pm 0.01$ & 0.0423 & $\uparrow$ \\
\hline \multirow[t]{2}{*}{351} & $P * 2$ & $0.04 \pm 0.01$ & 0.0079 & $\uparrow$ \\
\hline & $P * 14$ & $0.02 \pm 0.01$ & 0.0467 & $\uparrow$ \\
\hline 352 & $P * 2$ & $0.01 \pm 0.006$ & 0.0411 & $\uparrow$ \\
\hline 354 & $N B^{*} 2$ & $-0.02 \pm 0.004$ & $<0.0001$ & $\downarrow$ \\
\hline \multirow[t]{2}{*}{ ( $\beta$-Lactoglobulin) } & $N B^{*} 14$ & $-0.02 \pm 0.007$ & 0.0105 & $\downarrow$ \\
\hline & Heba*14 & $0.01 \pm 0.007$ & 0.0459 & $\uparrow$ \\
\hline
\end{tabular}

between the $S$. aureus challenge groups based on the FDR-adjusted $\mathrm{P}$-value $(\mathrm{P}<0.05)$. This spot, and four other spots that were differentially expressed over time and between the treatment groups based on their raw $\mathrm{P}$-values $(\mathrm{P}<0.05)$, were excised and subjected to
Table 1 Change in milk protein expression on 2 and 14 days post-intramammary infection with different S.aureus strains (Continued)

\begin{tabular}{ccccc}
\hline 355 & $N^{*} 2$ & $0.01 \pm 0.005$ & 0.0481 & $\uparrow$ \\
\hline 358 & $N B^{*} 2$ & $0.05 \pm 0.02$ & 0.0216 & $\uparrow$ \\
\hline 359 & $N B^{*} 2$ & $0.01 \pm 0.005$ & 0.0494 & $\uparrow$ \\
& $P^{*} 2$ & $0.01 \pm 0.005$ & 0.0474 & $\uparrow$ \\
\hline
\end{tabular}

NB, Newbould 305; P, Parent 3231; Heba, SCV Heba 3231

Trmt*Day denotes the treatment and day of the observed change in protein spot CPP3, component 3 of the proteose peptone

Data are presented as the least square mean \pm standard error of the mean $(\mathrm{LSM} \pm \mathrm{SEM})$.

Direction indicates the up-or down-regulation of the protein spot on day 2 or $14 \mathrm{pi}$, compared to baseline.

Spot I.D. number refers to protein spot number assigned by the Melanie software. Spots that were excised and identified by LC-MS/MS are indicated in parentheses.

protein sequencing by liquid chromatography and tandem mass spectrometry (LC-MS/MS). Identification of these protein spots and their expression patterns is summarized in Table 2 and Figure 3. Three out of the 5 spots were identified as component- 3 of the proteose peptone (CPP3). Two of the spots corresponding to CPP3 (spot \# 39 and 235) were up-regulated in animals challenged with Parent 3231 on day 2 and 14 pi $(\mathrm{P}<$ 0.05), as well as in the Heba 3231 challenge group on day $14 \mathrm{pi}$, with treatment differences occurring on day 14 pi between Newbould 305 and Parent 3231 or Heba 3231 challenge groups $(\mathrm{P}<0.05)$. In contrast, CPP3 (spot \# 349) was only up-regulated in the Newbould 305 challenge group on day $2 \mathrm{pi}(\mathrm{P}<0.01)$, with significant treatment differences occurring between the Newbould 305 and Heba 3231 challenge groups $(\mathrm{P}<0.05)$.

\section{Discussion}

The current study aimed to monitor the host immune response to $S$. aureus intramammary infection using three unique strains, and to identify potential candidates for targeted therapies that may modulate the host defense to $S$. aureus challenge. Intramammary infection with different strains of $S$. aureus resulted in variable cytokine responses within the bovine mammary gland and circulation, supporting our hypothesis that different strains of $S$. aureus prompt the activation of host immune responses that are unique to the infecting strain.

Typically, an increase in milk somatic cell count (SCC) is indicative of an elevated and sustained inflammatory response caused by intramammary infection. During acute mastitis for example, neutrophil numbers in the mammary gland increase dramatically, constituting > $90 \%$ of milk somatic cells [14], whereas somatic cells in healthy glands contain $<22 \%$ neutrophils [15]. CXCL-8/ IL-8 is the main tissue-derived chemoattractant for neutrophils [16,17]; however, our observations demonstrated 
Table 2 Identification of proteins differentially expressed in different S.aureus challenge groups 2 or 14 days postinfection

\begin{tabular}{|c|c|c|c|c|c|}
\hline Spot I.D. & Protein & NCBI Accession no. & MS result ${ }^{a}$ & Th. Mass $(\mathrm{kDa}) / \mathrm{pl}^{\mathbf{b}}$ & Obs. Mass $(\mathrm{kDa}) / \mathrm{pl}^{\mathrm{b}}$ \\
\hline 39 & Component PP3 & $2007376 \mathrm{~A}$ & $98 ; 13$ & $15.3 / 5.98$ & $16 / 6.5$ \\
\hline 235 & Component PP3 & $2007376 \mathrm{~A}$ & $115 ; 13$ & $15.3 / 5.98$ & $15 / 7$ \\
\hline 251 & $\beta$-casein precursor & P02666 & $72 ; 8$ & $25.1 / 5.26$ & $20 / 7$ \\
\hline 349 & Component PP3 & $2007376 A$ & 208; 39 & $15.3 / 5.98$ & $19 / 6$ \\
\hline 354 & $\beta$-lactoglobulin & CAA32835 & $109 ; 11$ & $20.3 / 4.85$ & $15 / 8$ \\
\hline
\end{tabular}

aon score is $=10^{*} \log (\mathrm{P})$ where $\mathrm{P}$ is the probability that the observed match is a random event (ion scores $>47$ are significant at $\mathrm{p}<0.05$ ); $\%$ coverage.

${ }^{\mathrm{b}}$ Theoretical (Th.) and observed (Obs.) masses and isoelectric points (pl).

that the bovine IL-8 response did not always parallel the somatic cell response during the different $S$. aureus intramammary infections. Somatic cell scores were significantly elevated throughout the study period, and peaked during the acute phase (days 2-5 pi) in all challenge groups (reported by Atalla et al., 2009 [18]), however, we did not observe significant induction of IL-8 in the casein-depleted milk at any point during the study period, and it was only detected in the serum on days 14 and 21 pi in animals challenged with Newbould 305 and Heba 3231. The lack of an IL-8 response in the milk is consistent with two previously reported independent studies carried out by Bannerman et al. (2004) and Riollet et al. (2000b) [19,20], suggesting that bovine IL-8

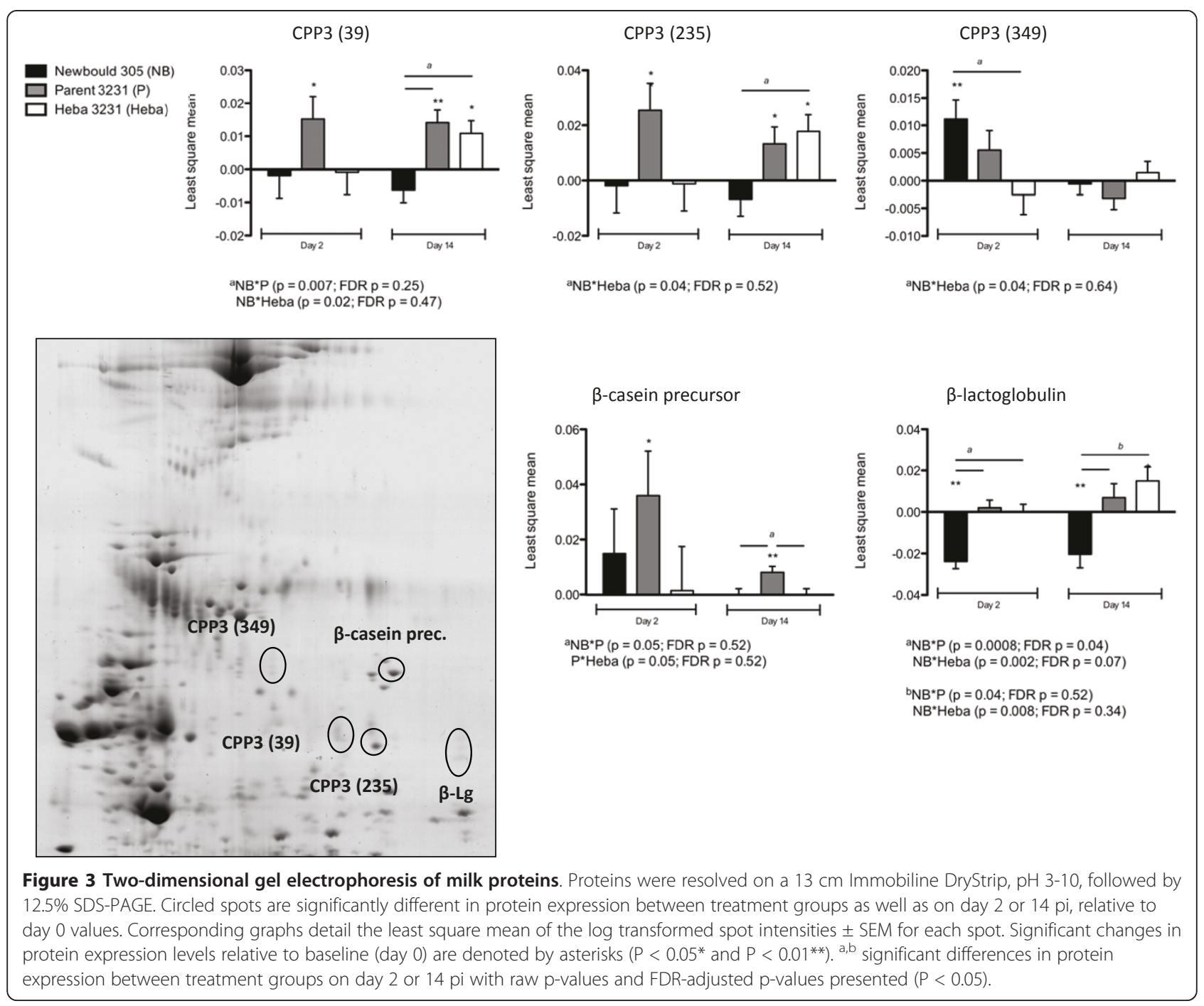


is not the only chemokine involved in trafficking neutrophils to the infected mammary gland. It is possible that other chemoattractants, such as complement cleavage factor 5a, IL-1 $\beta$, TNF- $\alpha$, CXCL1 and 3, and granulocytemacrophage colony stimulating factor (GM-CSF) produced by epithelial cells, macrophages and T cells, also contribute to neutrophil trafficking to the mammary gland during intramammary infection [21-23]. For instance, neutrophil infiltration into the bovine mammary gland may be mediated by IFN $-\gamma$ through the mechanism described by McLoughlin et al. (2008) [8] that involves CXC chemokines other than IL-8. Such chemokines may include CXCL1 and CXCL3, which are constitutively expressed in bovine milk [23]. In support of this, it has been demonstrated that IL- 8 and GM-CSF are not active chemokines during lactation, whereas other factors such as IL- $1 \beta$ and TNF- $\alpha$ are active during any stage of lactation $[22,24]$.

In the present study, IFN- $\gamma$ was found to be highly expressed both locally, as indicated by levels in the milk, and systemically during days 1-6 pi in animals challenged with Newbould 305, which parallels previously reported results by Bannerman et al. (2004) [19]. Serum IFN- $\gamma$ levels were significantly up-regulated in all challenge groups at day 21 pi compared to day 0 . This finding may be associated with the promotion of an enhanced cell-mediated immune response that includes neutrophil and macrophage activation.

During the chronic phase of infection, differences in serum TGF- $\beta 1$ expression between the three challenge groups were observed with notable increases being observed for the Parent 3231 and Heba 3231 groups. Milk TGF- $\beta 1$ did not significantly differ in response between any of the challenge groups; however, a trend towards altered TGF- $\beta 1$ expression in animals challenged with Newbould 305 was observed, whereby the cytokine levels reached a maximum at 48 hours pi (approximately $4000 \mathrm{pg} / \mathrm{ml}$, data not shown). This observation is in line with a previous report of milk TGF- $\beta 1$ kinetics upon Newbould 305 challenge in dairy cattle [25].

The role of TGF- $\beta$ in the host response to intramammary infection is uncertain because TGF- $\beta$ is a pleiotropic immunoregulatory cytokine, with both pro- and anti-inflammatory functions, depending on the location and activation state of the cells that it is interacting with [25]. This is exemplified by the cytokine's dual actions on macrophages. For instance, TGF- $\beta$ suppresses tissue macrophage function and inflammation by down-regulating the production of chemokines and cytokines such as IFN- $\gamma$ [26], up-regulating the expression of IL-1 receptor antagonist [27], and suppressing the production of cytotoxic reactive oxygen and nitrogen intermediates $[28,29]$. In contrast, TGF- $\beta$ has also been shown to promote inflammation by inducing chemotaxis in human peripheral blood monocytes [30,31], enhancing their ability for transendothelial migration to sites of infection [32], and up-regulating the transcription of pro-inflammatory cytokines such as IL-1 $\beta$ and TNF- $\alpha$. Furthermore, TGF- $\beta$ has been shown to be an important factor for the differentiation of a subset of effector Th cells known as Th17 cells, which elicit inflammatory responses during certain pathogenic infections that are not sufficiently dealt with by Th1 or Th2 immunity [33]. Lastly, regulatory cells including Tregs and M2 macrophages also produce TGF- $\beta$ in humans. These cells help to prevent the deleterious effects of prolonged or excessive host immune responses [34,35], and this process includes suppressing various components of the immune response such as antigen presentation by antigen presenting cells [36], and promoting tissue repair by increasing the deposition of extracellular matrix at the site of tissue injury, and promoting angiogenesis [37]. Since TGF- $\beta$ was not observed locally in the present study, it is unlikely that it was involved in repair of the mammary gland epithelium.

There is evidence to suggest that $S$. aureus may be able to modulate the host immune response in part by promoting TGF- $\beta$ expression; this could be a mechanism utilized by the Heba 3231 strain for example, to promote its survival within the host. In support of this, Staphylococcal superantigens (SAgs) have been demonstrated to induce the production of TGF- $\beta$ by initiating the differentiation and expansion of Tregs that downregulate the inflammatory response [38-40]. Indeed, TGF- $\beta$ has been implicated in playing a role in immunosuppression by up-regulating the expansion and/or activation of anergic regulatory $\mathrm{T}$ cells in the presence of $S$. aureus SAgs, which may disrupt class II MHC antigen presentation by APCs [41], limiting cell-mediated immunity. Interestingly, this immunomodulatory mechanism is also employed by Leishmania as a means to suppress cell-mediated immunity and promote its intracellular survival $[42,43]$. Lastly, it should be noted that TGF- $\beta$ expression may not necessarily denote its level of bioactivity, since a study by Kehrl et al. (1986) [44] demonstrated that human B cells largely express inactive TGF- $\beta$ in response $S$. aureus Cowan strain I.

Overall, haptoglobin concentrations increased with time in all challenge groups during the first 6 days of the study period, and declined to initial levels by days 14 and 21 pi. However, no significant differences in serum haptoglobin levels were observed between the challenge groups. This may have been due to the chosen sampling times, as no samples were taken between days 6 and 14 pi. It has been previously demonstrated that haptoglobin is up-regulated during the acute phase response, and that it may be used to discriminate 
between acute and chronic inflammation in cattle $[45,46]$. The findings in the present study indicate that overall serum haptoglobin levels were not significantly different between any of the challenge groups, suggesting that haptoglobin is a sensitive marker of inflammation due to $S$. aureus but it lacks specificity to discriminate the host response to the three different strains of $S$. aureus.

It was previously demonstrated that two common mastitis-causing pathogens, Escherichia coli and S. aureus, elicit different immune responses and pathogenesis [19]. Here, we demonstrate that the variability in immune protein response is also strain-specific, at least in the context of $S$. aureus. Further studies investigating the profiles of other cytokines will add to the results of the current study. Studying IL-17 and IL-6 for instance would provide insight into the involvement of Th17 cells in $S$. aureus infections, as IL-17 is a Th17 cytokine and IL-6, along with TGF- $\beta$ supports the differentiation of this Th subtype [47-49]. Furthermore, IL-6 is one of the major signals for the induction of the acute phase response [50], and may therefore compliment the present haptoglobin data. Monitoring chemoattractive factors, especially those under the regulation of TGF- $\beta$ (i.e. IL- $1 \beta$ and TNF- $\alpha$ ), would help delineate the pro- or anti-inflammatory role of TGF- $\beta$ in intramammary infection with different strains of $S$. aureus. Although it would have been interesting to measure IL-1- $\beta$ and TNF- $\alpha$ as well as other cytokines such as IL-4, IL-6, IL12 , and IL-10 that regulate the differentiation of these T-cell subpopulations, we had limited resources to carry out the cytokine analysis, and felt that inclusion of these cyctokies was beyond the scope of the current study as the aim was to note differences in host responses to different $S$. aureus strains, not to determine whether TGF$\beta$ is a pro- or anti-inflammatory cytokine.

In addition to seeing unique cytokine profiles in response to the different strains of $S$. aureus, the present study also found a number of milk proteins to be differentially expressed at various time-points in response to infection, including host defense proteins. Staphylococcus aureus insult to the mammary gland causes an inflammatory response that is characterized by an increase in vascular permeability, allowing exudates containing cells and proteins from the vasculature to enter the mammary gland [50]. Additionally, resident and recruited cells produce a number of proteins that target the pathogen and contribute to the restoration of homeostasis [50]. Therefore, the proteome of the milk may drastically change in response to pathogenic stimuli, and analysis of these changes may offer insight into the host response during mastitis. Indeed, the present study demonstrated changes in the milk proteome during intramammary infection with $S$. aureus. In order to assess protein expression in milk during the acute and chronic phases of infection, samples were evaluated on days 2 and 14 pi, respectively. Most proteins were upregulated following Newbould 305 and Parent 3231 challenges, especially on day 2 pi during the acute phase of infection. On day $14 \mathrm{pi}$, the number of up-regulated proteins was dramatically reduced in the Newbould 305 and Parent 3231 challenge groups, as compared to day 2 pi. Results from this study indicate that differences in milk protein expression also occur as a result of intramammary infection with different strains of $S$. aureus. On day 2 pi for example, challenges with Newbould 305 and Parent 3231 induced 12 milk proteins each, relative to day 0 . In contrast, significant changes in milk protein expression were not observed in response to challenge with Heba 3231 at this time. On day 14 pi however, 8 milk proteins were induced by challenge with the Parent 3231 strain and only 1 protein was induced by Newbould 305, whereas 8 proteins were significantly induced by the Heba 3231 challenge. These results are indicative of the acute pathogenic nature of the Parent 3231 and Newbould 305 strains and the unique phenotypic properties of SCVs, which may elicit a milder host response [18]. They suggest a highly active initial host response to challenges with the Parent 3231 and Newbould 305 strains, then perhaps resolution or establishment of chronic infection by day 14 pi. This corresponds with the somatic cell score data from these same cows presented by Atalla et al. (2009) [18], whereby the number of somatic cells in the milk during the chronic phase of infection still remained significantly up-regulated relative to day 0 . Interestingly, we were not able to detect an initial host response to the SCV strain, but the induction of protein expression was demonstrated on day 14 pi. This delayed and relatively low level of host response corresponds to the ability of the Heba 3231 strain to avoid recognition and persist within host cells [10]. Future studies should include later time points in order to determine if Heba 3231 continues to up-regulate milk protein expression.

Two of the five spots corresponded to the most abundant milk proteins - $\beta$-casein precursor and $\beta$-lactoglobulin. This finding is likely a result of incomplete depletion of these highly abundant proteins. Nonetheless, the depletion protocol was found to be sufficient to yield a comprehensive view of the milk proteome. Of the five protein spots that were subjected to identification by LC-MS/MS, only one protein, CPP3 also known as lactophorin, was implicated in host defense. Component 3 of the proteose peptone is a phosphoglycoprotein uniquely expressed in the mammary gland of lactating dairy cattle and can be found in bovine milk whey. It has been previously suggested to have several functions that include antimicrobial activity, inhibition of lipolysis, 
mitogenic activity, and immunostimulation [51-54]. It consists of seven polypeptide components, ranging in molecular weight from 17 to $67 \mathrm{kDa}[55,56]$. In the $2 \mathrm{DE}$ gels, it occurred at three different locations ranging in mass from 15-21 kDa and isoelectric point (pI) from 6-7 (Figure 3), which may correspond to its various components. In one study, the antimicrobial activity of CPP3 was investigated using a synthetic peptide called lactophoricin consisting of the 113-135 region of C-terminal of CPP3 [51]. Lactophoricin interacts with membrane phospholipids and forms voltage-dependent channels. Thus, it has been hypothesized that it may also be involved in the pore forming of natural lipid bilayers such as bacterial membranes [51,57]. Indeed, Campagna's results demonstrated that this peptide has inhibitory-growth effects on a number of Gram-positive and Gram-negative bacteria, with a more pronounced inhibitory effect on Gram-positive bacteria, including S. aureus [51].

\section{Conclusions}

The present study demonstrates the complexity of the host immune protein response to various strains of $S$. aureus. Intramammary infection with different strains of $S$. aureus, elicited unique host immune protein responses, as indicated by differential expression of the cytokines IL-8, TGF- $\beta$, and IFN- $\gamma$ in circulation and IFN- $\gamma$ in casein-depleted milk. In general, cytokines displayed heightened responses in the serum compared to the casein-depleted milk. Interestingly, the SCV strain, Heba 3231, showed increased levels of serum IL-8, IFN$\gamma$, and TGF- $\beta$ occurring during the later stages of infection (day $21 \mathrm{pi}$ ). Whether this pattern of induction continues in later time points has yet to be determined. Using a proteomic approach, we have also demonstrated that intramammary infection with three different strains of $S$. aureus elicits differential protein expression in bovine milk during the acute and chronic phases of infection. Intramammary infection with Newbould 305 and Parent 3231 strains resulted in pronounced induction of protein expression on day 2 pi, while the Heba 3231 strain elicited no protein induction at this time. On day 14 pi, host protein activity was less pronounced for animals challenged with Newbould 305 and Parent 3231 strains, while some induction occurred in animals challenged with Heba 3231. Lastly, CPP3, a potential antimicrobial peptide that is uniquely expressed in the bovine mammary gland during lactation, appeared on our 2DE gels as three different spots, which were differentially expressed between the various $S$. aureus treatment groups. These results demonstrate that different strains of $S$. aureus affect the proteome of the milk in different ways. Of specific interest was the unique response to the SVC, Heba 3231 on day 21 pi.
Therefore, investigating these changes in protein expression at later stages of infection is warranted. Overall, this study begins to shed light on the milk proteome and the changes that are elicited by intramammary infection with various strains of $S$. aureus and highlights an antimicrobial peptide, CPP3, which may have novel therapeutic potential.

\section{Methods}

\section{Selection of animals}

A detailed description of the selection criteria for cows used for intramammary infection has been previously described [18]. Briefly, healthy Holstein dairy cows (5 cows/treatment group) from the University of Guelph dairy herd and housed in the Ponsonby Research Station (Elora, Ontario, Canada) were selected for the studies under the following criteria: 1) quarter milk samples were negative for $S$. aureus; 2) quarter milk samples contained $\leq 500$ colony forming units (CFU) per $\mathrm{ml}$ of potential udder pathogens, other than $S$. aureus, that were mostly found in mixed culture; and 3) quarter milk samples had SCCs $<2 \times 10^{5}$ cells $/ \mathrm{ml}$. All cows were in their mid-to late-lactation and in the second or third trimester of gestation. They had no previous history of clinical mastitis and were in their first to fifth lactations. Animals were house in a tie-stall barn and fed a mixed ration formulated for the University dairy herd and milked twice daily. The study was approved by the University of Guelph Animal Care Committee.

\section{S. aureus intramammary challenge}

The $S$. aureus intramammary challenges were carried out between January and May of 2007. A detailed description of the preparation of $S$. aureus cultures and intramammary challenge is described by Atalla et al. (2009) [18]. Cows were randomly assigned to one of three treatments and then challenged with either SCV Heba3231, 3231 parent strain, or the Newbould 305. Three quarters (right front, right hind, and left hind) were infused with $\sim 1 \times 10^{3} \mathrm{CFU} / \mathrm{ml}$ of bacteria suspended in $5 \mathrm{ml}$ of ice-cold pyrogen-free PBS through the teat canal using a syringe fitted with a 1.5 inch teat infusion canula. The left front quarter was infused with $5 \mathrm{ml}$ of ice-cold pyrogen-free PBS, pH 7.4. The teats were then massaged in a dorsal direction and dipped in $1 \%$ iodine teat dip.

\section{Sample collection}

For this study, milk samples were only collected from the right hind quarter for analysis - the other two infected quarters and the saline quarter were used for sample collection by another group [18]. For collection, the teat was dipped in $1 \%$ iodine teat dip just prior to regular morning milking, fore-stripped by hand milking and the first two streams of milk were discarded. The 
teat was then wiped with a clean towel and scrubbed with gauze soaked in 70\% isopropyl alcohol, and milk samples were subsequently collected into sterile $50 \mathrm{ml}$ centrifuge tubes on day 0 before intramammary challenge, and days 1-6, 14, and 21 pi. Samples were kept at $4^{\circ} \mathrm{C}$ or on ice during transportation to the laboratory where they were immediately processed at $4^{\circ} \mathrm{C}$. For the preparation of casein-depleted milk, whole milk samples were centrifuged at $1500 \mathrm{~g}$ and $4^{\circ} \mathrm{C}$ for $30 \mathrm{~min}$. The top lipid layer was discarded and the remaining skim milk was stored at $-20^{\circ} \mathrm{C}$ until ultracentrifugation. For ultracentrifugation, milk samples were thawed at $4^{\circ} \mathrm{C}$ for 15 $17 \mathrm{hr}$, and centrifuged at $45,500 \mathrm{~g}$ at $4^{\circ} \mathrm{C}$ for $30 \mathrm{~min}$. The resulting casein-depleted milk was recovered and stored at $-20^{\circ} \mathrm{C}$ until used.

Approximately $10 \mathrm{ml}$ of blood from the tail vein of each cow was collected into vacutainers (SST Gel and Clot Activator from BD Biosciences, Mississauga, Ontario, Canada) on the mornings of days 0-6, 14, 21, 28 , and $35 \mathrm{pi}$. The samples were kept at $20^{\circ} \mathrm{C}$ for a maximum of 1 hour during transportation from the animal housing facility to the laboratory. Samples were then centrifuged at $1200 \mathrm{~g}$ at $20^{\circ} \mathrm{C}$ for $30 \mathrm{~min}$ to obtain sera and stored at $-80^{\circ} \mathrm{C}$ until used.

\section{Analysis of IL-8, TGF- $\beta 1$, and IFN- $\gamma$ in serum and casein- depleted milk}

Serum and milk cytokines were measured on days 0,1 , $2,4,6,14$, and 21 pi by ELISA. For IL-8, a commercially available human IL-8 ELISA kit (R\&D Systems Inc., Minneapolis, Minnesota, USA) was used to measure bovine IL- 8 in milk and serum samples according to the manufacturer's instructions with a slight modification. The antibodies used in the kit have been previously validated to cross-react with bovine IL-8 [58]. As the manufacturer's instructions were not optimized for use in milk, the sample incubation time for the analysis of IL-8 in casein-depleted milk was increased to $20 \mathrm{hr}$ at $4^{\circ} \mathrm{C}$. The inter- and intra-assay coefficients of variation for serum were $6 \%$ and $\leq 3 \%$, respectively, and for the milk they were $11 \%$ and $\leq 3 \%$, respectively. The limit of detection for this assay was $0.4 \mathrm{pg} / \mathrm{ml}$.

Serum and milk IFN- $\gamma$ concentrations were measured using a commercially available bovine IFN- $\gamma$ ELISA kit (Mabtech Inc., Cincinnati, Ohio, USA) according to the manufacturer's instructions. As the manufacturer's instructions were not optimized for use in milk, the sample incubation time for the analysis of IFN- $\gamma$ in casein-depleted milk was increased to $20 \mathrm{hr}$ at $4^{\circ} \mathrm{C}$. The inter- and intra-assay coefficients of variation for serum were $8 \%$ and $<4 \%$, respectively, and for the caseindepleted milk they were $6 \%$ and $\leq 6 \%$, respectively. The limit of detection for this assay was $9 \mathrm{pg} / \mathrm{ml}$.
Lastly, a commercially available human TGF- $\beta 1$ ELISA kit (R\&D Systems Inc.) that has been previously validated to cross-react with bovine TGF- $\beta 1$ by Ginjala and Pakkanen (1998) [59]. For activation of latent TGF- $\beta$ in caseindepleted milk, $0.1 \mathrm{ml}$ of undiluted casein-depleted milk was incubated with $0.1 \mathrm{ml}$ of $2.5 \mathrm{~N}$ acetic acid/10 M urea for $10 \mathrm{~min}$. Then $0.1 \mathrm{ml}$ of $2.7 \mathrm{~N} \mathrm{NaOH} / 1 \mathrm{M}$ HEPES was added to neutralize the reaction and the final solution was diluted 4-fold with Reagent Diluent Concentrate (R\&D Systems, Inc.). Casein-depleted milk samples were assayed according to the manufacturer's instructions with the exception of the sample incubation time, which was increased to $20 \mathrm{hr}$ at $4^{\circ} \mathrm{C}$. For serum TGF- $\beta 1$, serum samples were activated and diluted 10-fold with Reagent Diluent Concentrate (R\&D Systems Inc.). Samples were then assayed according to the manufacturer's instructions. The inter- and intra-assay coefficients of variation for serum were $7 \%$ and $\leq 3 \%$, respectively; for milk they were $6 \%$ and $\leq 3 \%$, respectively. The limit of detection for this assay was $8 \mathrm{pg} / \mathrm{ml}$.

\section{Haptoglobin}

Serum haptoglobin was quantified in samples collected on days $0,1,2,4,6,14$, and $21 \mathrm{pi}$, at the University of Guelph Animal Health Lab (Guelph, Ontario). Spectrophotometric quantification was based on the method developed by Makimura and Suzuki (1982) [60], which utilizes differences in peroxidase activity in free hemoglobin versus hemoglobin/haptoglobin conjugate.

\section{Milk proteome profiling by $2 \mathrm{D}$ gel electrophoresis}

For the preparation of milk for 2DE, casein-depleted milk samples were subjected to $\beta$-lactoglobulin ( $\beta$-Lactoglobulin) depletion by cyanogen bromide-activated Sepharose 4B conjugation with $\beta$-Lactoglobulin. In order to do this, a matrix was first prepared by washing $\mathrm{CNBr}$-activated Sepharose powder (GE Healthcare, Québec, Canada) with $200 \mathrm{ml}$ of $1 \mathrm{mM} \mathrm{HCl}$ for every $1 \mathrm{~g}$ of powder. The matrix was equilibrated with coupling buffer $\left(0.1 \mathrm{M} \mathrm{NaHCO}_{3}\right.$ containing $0.5 \mathrm{M} \mathrm{NaCl}, \mathrm{pH}$ 8.3) by rotating on a sample mixer for $20 \mathrm{~min}$ at $20^{\circ} \mathrm{C}$. The $\beta$ Lactoglobulin (Sigma-Aldrich, Oakville, Ontario, Canada) was dissolved in coupling buffer to a final concentration of $12 \mathrm{mg} / \mathrm{ml} \beta$-Lactoglobulin-coupled gel matrix. The dissolved $\beta$-Lactoglobulin solution and the equilibrated gel medium were mixed for $2 \mathrm{hr}$ at $20^{\circ} \mathrm{C}$. The reaction was quenched with $1 \mathrm{M}$ ethanolamine $(\mathrm{pH}$ 8.0) for $2 \mathrm{hr}$ at $20^{\circ} \mathrm{C}$. The mixture was centrifuged, and the supernatant was discarded without perturbing the $\beta$ Lactoglobulin-coupled gel medium. The coupled medium was washed with $0.1 \mathrm{M} \mathrm{NaCl} / \mathrm{HCl}(\mathrm{pH} 2)$ and then equilibrated with water for $20 \mathrm{~min}$ at $20^{\circ} \mathrm{C}$, centrifuged for $1 \mathrm{~min}$ at $16,000 \mathrm{~g}$ to pellet the beads, and the 
supernatant discarded without perturbing the medium. The matrix was stored at $4^{\circ} \mathrm{C}$ in $20 \%$ ethanol until used.

For $\beta$-Lactoglobulin depletion, $1 \times$ sample volume of sodium acetate buffer ( $\mathrm{pH} 4.6)$ was added to the samples, mixed, and centrifuged at $16,000 \mathrm{~g}$ for $30 \mathrm{~min}$ at $4^{\circ}$ C. The resulting supernatant was transferred to the CNBr-activated Sepharose 4B beads conjugated with $\beta$ Lactoglobulin, mixed on a rotating sample mixer for 20 min and centrifuged at $16,000 g$ to separate the $\beta$-Lactoglobulin-conjugated beads. The resulting supernatants were subjected to methanol-chloroform treatment to precipitate proteins. First, $2 \times$ the sample volume of methanol and $1 \times$ the sample volume of chloroform was added to the samples and proteins were allowed to precipitate for $1 \mathrm{hr}$ at $-20^{\circ} \mathrm{C}$. The samples were centrifuged, the upper phase was discarded and another round of methanol and chloroform was added to the remaining samples and mixed. The samples were centrifuged and the supernatants were discarded, and the resulting protein pellets were solubilized to a concentration of 200 $\mu \mathrm{g}$ protein $/ 250 \mu \mathrm{l}$ in rehydration solution containing 8 M urea, 2\% w/v CHAPS, $0.28 \% \mathrm{w} / \mathrm{v}$ DTT, $0.5 \% \mathrm{w} / \mathrm{v}$ IPG buffer (GE Healthcare), and bromophenol blue. Protein concentration was determined using a Nanodrop Spectrophotometer (Nanodrop Technologies, Wilmington, Delaware, USA).

For 2DE proteome profiling, the casein-depleted and $\beta$-Lactoglobulin-depleted milk samples were separated in the first dimension by isoelectric focusing (IEF) on 13 cm Immobiline DryStrips (pH 3-10; GE Healthcare) using the following protocol carried out at $20^{\circ} \mathrm{C}$ on an Ettan IPGphor IEF system (GE Healthcare). Strip rehydration was carried out for 2 hr then IEF was carried out at $30 \mathrm{~V}$ for $10 \mathrm{hr}, 100 \mathrm{~V}$ for $1 \mathrm{hr}, 300 \mathrm{~V}$ for $1 \mathrm{hr}$, $600 \mathrm{~V}$ for $1 \mathrm{hr}, 1000 \mathrm{~V}$ for $1 \mathrm{hr}, 3000 \mathrm{~V}$ for $1 \mathrm{hr}, 4000$ $\mathrm{V}$ for $2 \mathrm{hr}$, and $8000 \mathrm{~V}$ for $2 \mathrm{hr}$ at $50 \mu \mathrm{A} / \mathrm{strip}$. The strips were stored at $-80^{\circ} \mathrm{C}$ until the second-dimension separation. For separation in the second dimension, strips were equilibrated for $15 \mathrm{~min}$ in equilibration buffer containing 1.5 M Tris- $\mathrm{HCl}$ (pH 8.8), $6 \mathrm{M}$ Urea, 30\% v/v glycerol, $2 \% \mathrm{w} / \mathrm{v}$ SDS, bromophenol blue, and 1\% w/ $\mathrm{v}$ DTT. The strips were cast in $0.5 \% \mathrm{w} / \mathrm{v}$ agarose on $12 \%$ SDS-PAGE gels and run at $30 \mathrm{~mA} / \mathrm{gel}$. Protein migration was stopped when the dye front reached the bottom of the gels, and fixation was carried out overnight in 50\% methanol and 10\% acetic acid. The gels were stained with RAPIDstain (G-Biosciences, Maryland Heights, Missouri, USA) following the manufacturer's instructions and scanned using ImageScanner (GE Healthcare).

Gels were analyzed using Melanie 7.0 software (GeneBio, Geneva, Switzerland). Protein spot intensities were automatically background-subtracted on a spot basis, whereby the lowest $10^{\text {th }}$ percentile pixel value on the spot boundary was excluded from all other pixel values within the spot boundary. Spots were matched based on a hierarchical matching structure, as suggested in the Melanie 7.0 user manual.

The five protein spots of interest on the 2DE gels were excised using a scalpel. Spot reduction, akylation, tryptic digestion, and mass spectrometric analysis were performed at McGill University and Genome Québec Innovation Centre (Montréal, Québec, Canada). Excised spots were subjected to reduction, cysteine-alkylation and in-gel tryptic digestion using an automated MassPrep Workstation (Micromass UK Ltd., Wythenshawe, Manchester, UK) and a protocol previously described by Wasiak et al. (2002) [61]. Extracted peptides were then subjected to LC-MS/MS. First, peptides were injected into a $300 \mu \mathrm{m} \times 5 \mathrm{~mm}$ Zorbax C18 trapping column (Agilent Technologies, Mississauga, Ontario, Canada) and peptides were subsequently resolved on a $10 \mathrm{~cm} \times$ 75 micron PicoFrit column (New Objective, Inc., Woburn, Massachusetts, USA) containing C18 packing (BioBasic, Inc., Markham, Ontario, Canada). Peptides were eluted from the column with a 15 min gradient of $10-95 \%$ acetonitrile $(\mathrm{v} / \mathrm{v})$ containing $0.1 \%$ formic acid (v/ v) at a flow rate of $200 \mathrm{nl} / \mathrm{min}$ using an Agilent 1100 series NanoHPLC system (Agilent Technologies). Eluted peptides were electrosprayed as they exited the column. Mass spectrometric data were acquired on a QTRAP 4000 (Applied Biosystems, Streetsville, ON, Canada) using the Information Dependent Analysis feature of Analyst 1.4.1 software (Applied Biosystems). Briefly, up to three double, triple or quadruple charged ions of intensity greater than $2 \times 10^{6}$ counts per sec from each enhanced-MS survey scan were selected for passage into a collision cell. Collision-induced dissociation was facilitated by collision with nitrogen gas; fragment ions were trapped in quadrupole (Q)3 and scanned. Three enhanced-product ion scans at a speed of 4000 atomic mass unit/sec from 70 to $1700 \mathrm{~m} / \mathrm{z}$ were averaged for each selected precursor ion.

The tandem mass spectrometry raw data were transferred from the QTrap 4000 linear ion trap mass spectrometer to a server and automatically manipulated for generation of peak lists by employing the Distiller version 2.1.0.0 software http://www.matrixscience.com/distiller.html. The peak-listed data were then searched against the National Center for Biotechnology Information non-redundant database ftp://ftp.ncbi.nlm.nih.gov/ blast/db/ downloaded October 6, 2008) using the Mascot search engine version 2.1.04 http://www. matrixscience.com. The search was limited to the Mammalia taxonomy (Taxonomy ID 40674; 707975 sequences; 279723342 residues). 


\section{Statistical analyses \\ Cytokines and Haptoglobin}

The cytokine responses for each subject was assessed using the estimated area under the curve described by the change in response from days 1-6 compared to baseline. All data points were adjusted for baseline values by and subtracting day 0 readouts. These values were then log-transformed prior to analysis in order to stabilize the variance. The general linear model procedure was used to perform a statistical analysis of these estimates in addition to the change in response from the baseline (day 0) for days 14 and 21 pi, using SAS (SAS Institute Inc., Cary, North Carolina, USA). The Tukey-Kramer adjustment was used to perform pair-wise comparisons of the 3 treatments. Data are presented as the least square mean of the log-transformed values \pm standard error of the mean. For haptoglobin, repeated measurements taken over the course of 24 hours were analyzed using mixed models which included the 3 treatment groups as well the interaction between time and group, according to the method described by Wang and Goonewardene (2004) [62]. Changes were determined using day 0 as baseline values. The fixed effects were the 3 treatment groups, days and the interaction between treatment and day, and subject within treatment group was included as a random effect in the model. The MIXED procedure from SAS (SAS Institute Inc.) was used for analysis. Linear and quadratic orthogonal polynomial contrasts over time were used to assess differences in the responses between treatment groups. Data are presented as the least square mean of the log-transformed values \pm standard error of the mean.

\section{Milk proteomics}

The experimental design was a completely randomized design with three treatments of $S$. aureus and repeated measurements for each subject at days 0, 2 and 14. All raw values (spot intensity) were log transformed in order to stabilize the variances, and baseline (day 0) values were subtracted from days 2 and 14. The general linear model (GLM) procedure was used to assess differential expression of each protein spot between treatment groups on days 2 and $14 \mathrm{pi}$, relative to the average of day 0 values using SAS (SAS Institute Inc., Cary, NC, USA). Multiple comparisons between the 3 treatment groups were performed using Tukey-Kramer's adjustment. P-values from each comparison were then corrected based on the false discovery rate (FDR) adjustment using the MULTTEST procedure. Data are presented as the least square mean of the log transformed values \pm standard error of the mean.

\section{Acknowledgements}

We thank Catherine Gravel at Université Laval and Qiumei You at the University of Guelph for their technical assistance. We would also like to thank Dr. Margaret Quinton for her assistance with statistical analyses. Funding was provided by the Canadian Bovine Mastitis Research Network.

\section{Author details}

${ }^{1}$ Center for Genetic Improvement of Livestock, Department of Animal and Poultry Science, University of Guelph, Guelph, Ontario, N1G 2W1, Canada. ${ }^{2}$ Department of Pathobiology, Ontario Veterinary College, University of Guelph, Guelph, Ontario, N1G 2W1, Canada. ${ }^{3}$ Centre de recherche en biologie de la reproduction, Pavillon des Services, INAF, Université Laval, Québec, G1V 0A6 Canada.

\section{Authors' contributions}

YK coordinated and performed experiments. HA performed the animal infections and cultured the bacteria. BM, CR, and NK designed and coordinated the project. All authors drafted the manuscript and approved its content.

Received: 23 March 2011 Accepted: 1 September 2011 Published: 1 September 2011

\section{References}

1. DeGraves FJ, Fetrow F: Economics of mastitis and mastitis control. Vet Clin North Am 1993, 9:421-434.

2. Santos JE, Cerri RL, Ballous MA, Higginbotham GE, Kirk JH: Effect of timing of first clinical mastitis occurrence on lactational and reproductive performance of Holstein dairy cows. Anim Reprod Sci 2004, 80:31-45.

3. Barkema HW, Schukken YH, Zadoks RN: Invited Review: The role of cow, pathogen, and treatment regimen in the therapeutic success of bovine Staphylococcus aureus mastitis. J Dairy Sci 2006, 89:1877-1895.

4. Sutra L, Poutrel B: Virulence factors involved in the pathogenesis of bovine intramammary infections due to Staphylococcus aureus. J Med Microbiol 1994, 40:79-89.

5. Finlay $B B$, Cossart $P$ : Exploitation of mammalian host cell functions by bacterial pathogens. Science 1997, 276:718-725.

6. Almeida RA, Matthews KR, Cifrian E, Guidry AJ, Oliver SP: Staphylococcus aureus invasion of bovine mammary epithelial cells. J Dairy Sci 1996, 79:1021-1026.

7. Gresham HD, Lowrance JH, Caver TE, Wilson BS, Cheung AL, Lindberg FP: Survival of Staphylococcus aureus inside neutrophils contributes to infection. J Immunol 2000, 164:3713-3722.

8. McLoughlin RM, Lee JC, Kasper DL, Tzianabos AO: IFN-gamma regulated chemokine production determines the outcome of Staphylococcus aureus infection. J Immunol 2008, 181:1323-1332.

9. Proctor RA, Kahl B, von Eiff C, Vaudaux PE, Lew DP, Peters G: Staphylococcal small colony variants have novel mechanisms for antibiotic resistance. Clin Infect Dis 1998, 27(Suppl 1):S68-S74.

10. Atalla H, Gyles C, Jacob CL, Moisan H, Malouin F, Mallard B: Characterization of a Staphylococcus aureus small colony variant (SCV) associated with persistent bovine mastitis. Foodborne Pathog Dis 2008, 5:1-15.

11. Looney WJ: Small-colony variants of Staphylococcus aureus. Br J Biomed Sci 2000, 57:317-322.

12. Newbould FH: Antibiotic treatment of experimental Staphylococcus aureus infections of the bovine mammary gland. Can J Comp Med Vet Sci 1974, 38:411-416.

13. Smith EM, Green LE, Medley GF, Bird HE, Fox LK, Schukken YH, Kruze JV, Bradley AJ, Zadoks RN, Dowson CG: Multilocus sequence typing of intercontinental bovine Staphylococcus aureus isolates. J Clin Microbiol 2005, 43:4737-43.

14. Saad AM, Ostensson K: Flow cytofluorometric studies on the alteration of leukocyte populations in blood and milk during endotoxin-induced mastitis in cows. Am J Vet Res 1990, 51:1603-1607.

15. Riollet C, Rainard P, Poutrel B: Cell subpopulations and cytokine expression in cow milk in response to chronic Staphylococcus aureus infection. J Dairy Sci 2001, 84:1077-1084.

16. Baggiolini M, Clark-Lewis I: Interleukin-8, a chemotactic and inflammatory cytokine. FEBS J 1992, 307:97-101

17. Mukaida N, Harada A, Matsushima K: Interleukin-8 (IL-8) and monocyte chemotactic and activating factor (MCAS/MCP-1), chemokines essentially involved in inflammatory and immune reactions. Cytokine Growth Factor Rev 1998, 9:9-23. 
18. Atalla H, Gyles C, Wilkie B, Leslie K, Mallard B: Somatic cell scores and clinical signs following experimental intramammary infection of dairy cows with a Staphylococcus aureus small colony variant (S. aureus SCV) in comparison to other bovine strains. Vet Microbiol 2009, 137:326-34.

19. Bannerman DD, Paape MJ, Lee JW, Zhao X, Hope JC, Rainard P: Escherichia coli and Staphylococcus aureus elicit differential innate immune responses following intramammary infection. Clin Diagn Lab Immunol 2004, 11:463-472.

20. Riollet C, Rainard P, Poutrel B: Differential induction of complement fragment $\mathrm{C} 5 \mathrm{a}$ and inflammatory cytokines during intramammary infections with Escherichia coli and Staphylococcus aureus. Clin Diagn Lab Immunol 2000, 7:161-167.

21. Oviedo-Boyso J, Valdez-Alarcon JJ, cajero-Juarez M, Ochoa-Zarzosa A, Lopex-Meza JE, Bravo-Patino A, Baizabal-Aguirre VM: Innate immune response of bovine mammary gland to pathogenic bacteria responsible for mastitis. J Infect 2006, 54:399-409.

22. Rainard P, Riollet C: Mobilization of neutrophils and defense of the bovine mammary gland. Reprod Nutr Dev 2003, 43:436-457.

23. Rainard $P$, Riollet $C$, Berthon P, Cunha P, Fromageau A, Rossignol C, Gilbert FB: The chemokine CXCL3 is responsible for the constitutive chemotactic activity of bovine milk for neutrophils. Mol Immunol 2008, 45:4020-7.

24. Persson K, Colditz IG, Flapper P, Franklin NA, Seow HF: Cytokine-induced inflammation in the ovine teat and udder. Vet Immunol Immunopathol 1996, 53:73-85.

25. Bannerman DD, Paape MJ, Chockalingham A: Staphylococcus aureus intramammary infection elicits increased production of transforming growth factor - a1, b1, and b2. Vet Immunol Immunopathol 2006, 112:309-315.

26. Fargeas C, Wu CY, Nakajima T, Cox D, Nutman T, Delespesse G: Differential effect of transforming growth factor beta on the synthesis of Th1- and Th2-like lymphokines by human T lymphocytes. Eur J Immunol 1992, 22:2173-2176.

27. Turner M, Chantry D, Katsikis P, Berger A, Brennan FM, Feldmann M: Induction of the interleukin 1 receptor antagonist protein by transforming growth factor-beta. Eur J Immunol 1991, 21:1635-1639.

28. Ashcroft GS: Bidirectional regulation of macrophage function by TGFbeta. Microbes Infect 1999, 1:1275-1282.

29. Letterio JJ, Roberts AS: Regulation of immune responses by TGF-b. Annu Rev Immunol 1998, 16:137-161.

30. McCartney-Francis N, Mizel D, Wong H, Wahl L, Wahl S: TGF-beta regulates production of growth factors and TGF-beta by human peripheral blood monocytes. Growth Factors 1990, 4:27-35.

31. Wall RJ, Powell AM, Paape MJ, Kerr DE, Bannerman DD, Pursel VG, Wells KD, Talbot N, Hawk HW: Genetically enhanced cows resist intramammary Staphylococcus aureus infection. Nat Biotechnol 2005, 23:445-451.

32. Wahl SM, Allen JB, Weeks BS, Wong HL, Klotman PE: Transforming growth factor beta enhances integrin expression and type IV collagenase secretion in human monocytes. Proc Natl Acad Sci USA 1993, 90:4577-4581

33. Korn T, Bettelli E, Oukka M, Kuchroo VK: IL-17 and Th17 Cells. Annu Rev Immunol 2009.

34. Benoit M, Desnues B, Mege JL: Macrophage polarization in bacterial infections. J Immunol 2008, 181:3733-9.

35. Cools N, Ponsaerts P, Van Tendeloo VF, Berneman ZN: Regulatory T cells and human disease. Clin Dev Immunol 2007, 2007:89195.

36. Delvig AA, Lee JJ, Chrzanowska-Lightowlers ZM, Robinson JH: TGF-beta1 and IFN-gamma cross-regulate antigen presentation to CD4 T cells by macrophages. J Leukoc Biol 2002, 72:163-6.

37. Roberts AB, Sporn MB, Assoian RK, Smith JM, Roche NS, Wakefield LM, Heine UI, Liotta LA, Falanga V, Kehrl JH, et al: Transforming growth factor type beta: rapid induction of fibrosis and angiogenesis in vivo and stimulation of collagen formation in vitro. Proc Natl Acad Sci USA 1986, 83:4167-71.

38. Birebent B, Lorho R, Lechartier $\mathrm{H}$, deGuibert $\mathrm{S}$, Alizade M, Vu N, Beauplet A, Robillard N, Semana G: Suppressive properties of human CD4+CD25+ regulatory T cells are dependent on CTLA-4 expression. Eur J Immunol 2004, 34:3485-3496.

39. Tang Q, Boden EK, Henriksen KJ, Bour-Jordan H, Bi M, Bluestone JA: Distinct roles of CTLA-4 and TGF-b in CD4+CD25+ regulatory T cell function. Eur $\mathrm{J}$ Immunol 2004, 34:2996-3005.
40. Zhang L, Huanfa Y, Xia XP, Zhao Y: Transforming growth factor-beta: an important role in CD4+CD25+ regulatory $T$ cells and immune tolerance. Autoimmunity 2006, 39:269-276.

41. Chang BS, Bohach GA, Lee SU, Davis WC, Fox LK, Ferens WA, Seo KS, Koo HC, Kwon NH, Park YH: Immunosuppression by T regulatory cells in cows infected with Staphylococcal superantigen. J Vet Sci 2005, 6:247-250

42. Czarniecki CW, Chiu HH, Wong GH, McCabe SM, Palladino MA: Transforming growth factor-beta 1 modulates the expression of class II histocompatibility antigens on human cells. J Immunol 1988, 140:4217-4223.

43. Gollnick SO, Cheng HL, Grande CC, Thompson D, Tomasi TB: Effects of transforming growth factor-beta on bone marrow macrophage la expression induced by cytokines. J Interferon Cytokine Res 1995, 15:485-91

44. Kehrl JH, Roberts AB, Wakefield LM, Jakowlew S, Sporn MB, Fauci AS: Transforming growth factor beta is an important immunomodulatory protein for human B lymphocytes. J Immunol 1986, 137:3855-3860.

45. Gronlund U, Hulten C, Eckersall PD, Hogarth C, Persson Waller K: Haptoglobin and serum amyloid $A$ in milk and serum during acute and chronic experimentally induced Staphylococcus aureus mastitis. J Dairy Res 2003, 70:379-86.

46. Horadagoda NU, Knox KM, Gibbs HA, Reid SW, Horadagoda A, Edwards SE, Eckersall PD: Acute phase proteins in cattle: discrimination between acute and chronic inflammation. Vet Rec 1999, 144:437-441.

47. Bettelli E, Carrier Y, Gao W, Korn T, Strom TB, Oukka M, Weiner HL, Kuchroo VK: Reciprocal developmental pathways for the generation of pathogenic effector TH17 and regulatory T cells. Nature 2006, 441:235-8.

48. Mangan PR, Harrington LE, O'Quinn DB, Helms WS, Bullard DC, Elson CO, Hatton RD, Wahl SM, Schoeb TR, Weaver CT: Transforming growth factorbeta induces development of the $T(\mathrm{H}) 17$ lineage. Nature 2006, 441:231-4.

49. Veldhoen M, Hocking RJ, Atkins CJ, Locksley RM, Stockinger B: TGFbeta in the context of an inflammatory cytokine milieu supports de novo differentiation of IL-17-producing T cells. Immunity 2006, 24:179-89.

50. Kindt TJ, Goldsby RA, Osborne BA: Kuby Immunology. New York: WH Freeman and Company; 1992.

51. Campagna S, Mathot AG, Fleury Y, Girardet JM, Gaillard JL: Antibacterial activity of lactophoricin, a synthetic 23-residues peptide derived from the sequence of bovine milk component-3 of proteose peptone. J Dairy Sci 2004, 87:1621-6.

52. Girardet JM, Linden G, Loye S, Courthaudon JL, Lorient D: Study of mechanism of lipolysis inhibition by bovine milk proteose-peptone component 3. J Dairy Sci 1993, 76:2156-63.

53. Mati A, Moulti-Mati F, Girardet JM, Fokou E, Belleville-Nabet F, Nabet $P$, Linden G: Mitogenic activity of hydrophobic frations of proteose peptone from cows', ewes', and goats' milk measured with MARK 3 hybridoma culture. J Dairy Res 1993, 60:443-448.

54. Sugahara T, Onda H, Shinohara Y, Horii M, Akiyama K, Nakamoto K, Hara K: Immunostimulation effects of proteose-peptone component 3 fragment on human hybridomas and peripheral blood lymphocytes. Biochim Biophys Acta 2005, 1725:233-40.

55. Kanno C: Characterization of multiple forms of lactophorin isolated from bovine milk whey. J Dairy Sci 1989, 72:1732-9.

56. Park TJ, Kim JS, Choi SS, Kim Y: Cloning, expression, isotope labeling, purification, and characterization of bovine antimicrobial peptide, lactophoricin in Escherichia coli. Protein Expr Purif 2009.

57. Campagna S, Cosette P, Molle G, Gaillard JL: Evidence for membrane affinity of the C-terminal domain of bovine milk PP3 component. Biochim Biophys Acta 2001, 1513:217-22.

58. Shuster DE, Kehrli ME Jr, Rainard P, Paape M: Complement fragment C5a and inflammatory cytokines in neutrophil recruitment during intramammary infection with Escherichia coli. Infect Immun 1997, 65:3286-92.

59. Ginjala V, Pakkanen R: Determination of transforming growth factor-beta 1 (TGF-beta 1) and insulin-like growth factor (IGF-1) in bovine colostrum samples. J Immunoassay 1998, 19:195-207.

60. Makimura S, Suzuki N: Quantitative determination of bovine serum Haptoglobin and its elevation in some inflammatory diseases. Nippon Juigaku Zasshi 1982, 44:15-21.

61. Wasiak S, Legendre-Guillemin V, Puertollano R, Blondeau F, Girard M, de Heuvel E, Boismenu D, Bell AW, Bonifacino JS, McPherson PS: Enthoprotin: 
a novel clathrin-associated protein identified through subcellular proteomics. J Cell Biol 2002, 158:855-62.

62. Wang $Z$, Goonewardene L: The use of MIXED models in the analysis of animal experiments with repeated measures data. Can J Anim Sci 2004, 84:1-11.

doi:10.1186/1746-6148-7-51

Cite this article as: Kim et al: Changes in Holstein cow milk and serum proteins during intramammary infection with three different strains of Staphylococcus aureus. BMC Veterinary Research 2011 7:51.

Submit your next manuscript to BioMed Central and take full advantage of:

- Convenient online submission

- Thorough peer review

- No space constraints or color figure charges

- Immediate publication on acceptance

- Inclusion in PubMed, CAS, Scopus and Google Scholar

- Research which is freely available for redistribution

Submit your manuscript at www.biomedcentral.com/submit 